Invited paper and award paper

\title{
The São Paulo Declaration (1998): Nothing Dates More Rapidly than the Present
}

\author{
Chris Rojek ${ }^{1}$, Cesar Teixeira Castilho ${ }^{2,3}$
}

${ }^{1}$ U1City University-Sociology, United Kingdom of Great Britain na Northern Ireland, UK; ${ }^{2}$ Universidade

Federal de São João Del Rei, UFSJ, Physical Education, São João Del Rei, MG, Brazil; ${ }^{3}$ Universidade

Federal de Minas Gerais, UFMG, Physical Education, Belo Horizonte, MG, Brazil

\begin{abstract}
The Sao Paulo Declaration (1998) committed leisure professionals to extending Rights, Inclusion and Social Order in leisure customs and practice. The engine for this intervention consisted of the twin processes of globalization and cosmopolitanism. Both were seen as dissolving economic and political barriers. The Declaration did not make use of the term 'world society'. On the other hand it clearly defined itself to be part of a global movement that addressed leisure for all. In the last 20 years, the progress made $n$ fulfilling the terms of the Declaration has been disappointing. Economic barriers of wealth inequality and uneven development in globalization and cosmopolitanism have blocked many aspects of the Rights, Inclusion and Order articulated in the Declaration. This paper examines how far globalization and cosmopolitanism have progressed in achieving the principle that 'all persons have the right to leisure.' It examines data on wealth inequality, debt and unemployment rates to consider some of the concrete impediments. It concludes by maintaining that there is a need to go beyond the Sao Paulo Declaration by addressing the economic and political barriers that currently prevent leisure from being a right for all.
\end{abstract}

Keywords: São Paulo Declaration (1998), leisure, rights, inclusion, social order, globalization.

\section{Introduction}

Can it be only 20 years ago that the World Leisure and Recreation Association issued the famous 'Sao Paulo Declaration' (WLRA 1995)? This called upon 'the United Nations, all governments, all non-government organizations, World Leisure members and all citizens of the world' to accept and promote 'the 10 Articles'. Article 1 states: 'All persons have the right to leisure through economic, political and social policies that are equitable and sustainable.'

This is the foundation of the Declaration. Upon it, the other 9 articles follow. In order to facilitate comprehension, these can be organized into three meta-themes:

1) Inclusion

The right of all persons to celebrate and share diversity in leisure is confirmed. To this end, governments and institutions (private and public sectors) are called upon to "preserve and create barrier free environments' to permit free movement and participation in leisure culture and practice.

2) Rights

Participation in leisure is redefined as a matter of Human Rights. All governments and institutions (private and public sectors) are called upon to 'enact and enforce' laws and policies that will provide 'leisure for all'. Moreover, it also declares 'participation in the cultural life of the community' as a right.

3) Order

All governments and institutions (private and public sectors) must guarantee the integrity of leisure by a) taking appropriate measures against forms and practices of leisure which are 'deviant and criminal'; and b) monitoring 'threats' to the diversity and quality forms and practice of leisure caused by 'the national and international consequences of globalization.'
The Declaration adopts the tenor that the world is moving rapidly into a uniform new order. The nation-state is loosing its relevance and becoming supplemented by various multiple and exponential forms of transnational flows and links. These are held to have the effect of dismantling cultural barriers and opening up new opportunities for wealth creation. The ambitious objective in Article 1 of producing leisure, which is 'equitable' and 'sustainable' for all, implies that it is realistic to propose that a global leisure dividend is being created. The expectation is that it is both the advantaged and the disadvantaged are set to receive more leisure resources. Naturally, there are issues to be resolved with the respect to the ratio of resource allocation between strata. Irrespective of this, the founding principle of the Declaration, that 'all persons have the right to leisure' clearly indicates that Inclusion, Rights and Order, is understood to apply to all. Analytically speaking, the Declaration may be read as a response among leisure professionals to new disaggregated global challenges by aggregating them around a set of rational-ethical parameters. The parameters are of a particular kind. They are value-laden, in a good sense. That is, around their ordinance, the 10 Articles, in conjunction with governments around the world, look forward to constructing the conditions for unity, tolerance and peaceful leisure practice and experience. Although the details are not particularized, the whole tone of the Declaration implies an enhanced role for transnational leisure organizations and bilateral and multilateral forms of government. It is hard to see what other arrangement could deliver on the attainment and monitoring of issues relating to Inclusion, Rights and Order. But since this applies to the world order, it logically implies that leisure professionals must take a position on the persistence of presently existing autocracies and plutocracies. For the continued existence of these governments 
infringe on the right, integrity and freedom of leisure for all. Significantly, the Declaration maintains silence on this point.

The twin central pillars of the emerging world framework envisaged by the Declaration are globalization and cosmopolitanism. These are understood as non-linear, dialectical processes, which transform the global conditions of life. The Declaration proceeds on the basis that globalization is a universal transformative process which is changing the nature of local experience, the meaning of time and space and the character of moral life-worlds ${ }^{1,2,3}$. Whatever one might think of the nature of the relationships between the local and the global, or how they might develop, the nucleus of globalization (as it pertains to intentionality, behaviour and outlook), is 'overwhelming interconnectivity" ${ }^{4}$. This condition, with its palpable implications for capital flows, migration, data exchange and risk, is very much the decisive context in which the Declaration was prepared and published. Tacitly, globalization is assumed to be an inevitable process. There are three (unspecified) reasons for this. Firstly, globalization is held to maximize economic resource development by supporting the free movement of labour, capital and data. Secondly, globalization is believed to reduce the risk of nationalist military events by dissolving cultural, religious, political and nationalist barriers. Thirdly, globalization is said to enhance the development of judicial standards of universal justice by educating nations to the political interests and political determinations of other nations. The question for leisure professionals then, is not how to halt globalization. Rather, it is how to shape it in order to ensure that national leisure forms and practices are not co-opted or vapourized, and the vacant space turned into a sort of deterritorialized, commercially driven, monolithic, 'leisure mega-world'.5

In 1998 this was seen as the looming battle for Leisure Studies. It is the reason why Article 6, of the Declaration insists upon the need to monitor 'threats to the diversity and quality of leisure'. Article 7, augments this with an undertaking to develop vigilance about potential abuses of leisure resulting from 'local, national and international forces.' Nowhere in the Declaration does the term 'cosmopolitan' occur. Yet the form of social consciousness of which it is an expression clearly recognizes the possibilities of trans-national forms of leisure experience and practice that universally observe the combined ordinance of unity, tolerance, peace and order. A clear interventionist and managerial role for leisure professionals is presupposed here, but the details of how it will be organized and enacted remain obscure.

The Declaration is indeed, an expression of what is now called cosmopolitanism. This is a many-sided concept ${ }^{6,7,8}$. Various attempts have been made to pinpoint its key features. These include acknowledging that the world is moving into a position in which geographical proximity, as realized within the boundaries of the nation state, no longer has prior, or privileged, moral or necessarily, legal and judicial, purchase 9. Trans-national loyalties and responsibilities to 'humanity as a whole' are said to be emerging as paramount ${ }^{10[1]}$. What it means to be free (or freer) from 'geographical proximity' to the nation-state, or how trans-national loyalties may be applied to 'humanity as a whole', is nebulous. Despite this, cosmopolitans clearly take the view that the global expansion of capitalism, through greater physical mobility and the rise of digital communication, places intolerable burdens on the concept of the nation state as it has been traditionally conceived. The social determinations attached to the notion of a geo-political entity separated from others by inviolate territorial boundaries are no longer absolutely tenable. Regarding the all-important flow of ideas, technologies, finance, cultures and, to a large extent, people, no nation-state is insulated. It is not so much that people opt to engage with different identities, new forms of collective order, new ways of being and new solidarities. Rather, the new technologies, capital flows and communication networks of globalization make engagement impossible to avoid, or defer. The inference is that technology, capital flows and communication networks are at the root of cosmopolitanism, just as they are the driving forces behind globalization. This point requires qualification. It is not technology and communication networks that produce cosmopolitan consciousness, but rather, cosmopolitan consciousness that seeks to interpret and frame technology and communication networks around rational-ethical imperatives. Technological developments, capital flows and the growth of communication networks may lead the world into this or that direction. What makes the status of flow meaningful is how it is noticed and interpreted in the balance i.e. how it is communicated and rationalized. This suggests that the impact of globalization and cosmopolitanism is not a matter of fiat i.e. in this case, the assumption that technology and communication networks will bring the world's population closer in their leisure, work, community values etc. Rather impact must be measured and understood through the articulation and, presumably, (quantifiable and qualitative) measurement, of cosmopolitan and global values, beliefs and practices in the concrete, material conditions and ways of life.

Strictly speaking, no person, whether he or she be cosmopolitan in his/her outlook, or not, is independent of new technologies, communication networks and capital flows. Compared with Westerners, Amazonian tribesmen, and North Korean citizens who currently under the supreme leader, Kim Jong-un, may be said to live in positions of severely restricted access to global technologies, capital flows and communication networks. However, it strains credulity to propose that they can escape the gravitational pull of these forces. Even if they do not understand fully, or even significantly, what articulations of cosmopolitanism might mean to their own lives, many of the most important consequences of globalization reduces them to a position of equivalence with the rest of the world's

[1] Nussbaum is one of strongest advocates of cosmopolitanism. She sees the latter as culminating in world citizenship, which is assumed to be superior to more local bonds e.g. ethnic, regional and national solidarities. In this version of cosmopolitanism, local bonds are defended, but only to the extent that they do not conflict with cosmopolitan imperatives. This 'strong' version of cosmopolitanism has been much criticized for unintentionally introducing a latent form authoritarianism in the management of world affairs ${ }^{54}$. 
population. Indeed, the Declaration is perfectly right to suggest that certain aspects of the twin processes of globalization and cosmopolitanism make it valid to analyze conditions in terms of 'world society' ${ }^{[2]}$. To cite the most obvious one, the main lesson that globalization imparts, namely, the increasing significance of overwhelming interconnectivity, also applies to the common risks of wellbeing and survival that humans face. Unarguably, technological, chemical, biological and nuclear enterprise delivers much. By the same token, it introduces shared hazard into common global relations. The effects of global environmental risks are not confined to the nations that produce them ${ }^{11}$. The omnipresence of global risk means that it behoves anyone who is in a position to do so, to become at least semi-literate about the lives of others, and conversant with the local conditions that apply to them.

While it is legitimate to nominate self-interest as part of the cosmopolitan outlook, it is not the only, or even the principal component. The lives of others have a higher profile in social consciousness because they constitute a greater portion of the texture of the consciousness and practice of everyday life. There are various reasons for this. The expansion of the mass media and the rapid rise of social media, multiply and expand data flows. Travel and tourism have brought more people into contact with cultures of difference. Even if this does not entail direct involvement in the sense of having physical contact with others, mass communications and social media have revolutionized para-social relations ${ }^{[3]}$. That is, the network of emotional relations conducted through electronic systems of communication between people who are otherwise, in terms of geography, culture and religion, remote ${ }^{12}$. This is compatible with an immense multiplication in relationships of presumed intimacy between people whose only contact is through electronic media ${ }^{13}$. The number of direct contacts we have with others through Facebook, Instagram, Snapchat etc is actually only a very small part of what is involved here. They are out-numbered by the para-social relations we have with statistical men and women ${ }^{14}$. That is, men and women with whom we have anonymous, one-sided contact, which significantly adds to our mental map of the lives of others. All of this has contributed to greater social consciousness about difference and diversity, without necessarily adding very much to an understanding in depth.

Para-social relationships are a major feature of cosmopolitanism. However, the spread of ethnic and cultural diasporas into the West, in the form of long-term or permanent settlers should not be under-estimated. In the metropolitan centres of the core capitalist nations, significant multi-cultural and multi-ethnic populations have arrived from far afield and settled. Frequently, the religious customs, dress codes, cuisine, etc that they have brought with them, offer immediate, and pointed, contrasts with Western traditions and conventions. This condition produces a form of

[2] This term is not used in the Declaration. However, the logical outcome of the 10 Articles cumulatively point inescapably to this as a desired end of globalization and cosmopolitanism.

[3] The term was coined by Horton and Wohl ${ }^{55}$. Writing at the dawn of the television age, they used it to refer to the emotional relationships that tv audiences were forging with tv presenters. Para-social relationships were the first stage in what we no call 'mediated identity'. social consciousness which is a variant of W.B. Du Bois's ${ }^{15}$ famous concept of 'double consciousness'. Developed in relation to the position of African Americans who are simultaneously divided in feeling that they belong to more than one world, Du Bois intended the concept to convey the sense of being both at 'home' and 'abroad', 'here' and 'there', 'unified' and 'separate', 'together' and 'apart'. Plantation-slave culture imbued race relations in America with a heavy cargo of mental and social divisions. The Cosmopolitan outlook parallels this perspective. It encompasses the dimensions of race and ethnicity, but it is not limited to them. Rather it refers to the whole way of thinking about, and engaging with, cultural difference ${ }^{16}$. Where culture is no longer monolithic and has moved into a concrete, material multi-cultural condition, there is very likely to be a good deal of regret and sentimentality about the old reality that has been replaced with the new reality. The Declaration refers to 'the abuse and misuse' of leisure customs and practice by globalization and cosmopolitanism, but it fails to supply tactics or procedures to minimize the advent of resentment arising from feelings that the old world has been lost.

In the study of leisure there are many contributions, which highlight the trend of globalization in tourism, sport and media 17,18,19. There is every reason to believe that many more will follow. For, unquestionably, the Declaration was correct in highlighting the opportunities and challenges that the two interrelated processes pose for the quality and cohesion of leisure customs and practice. One assumption it made is that a universal conceptual currency is likely to emerge to comprehend and evaluate questions of morality in leisure customs and practice and the impact of globalization upon them. By this is meant that comprehension is understood and examined as belonging to a unitary, continuous, conjoined, logical space, that avoids segregation from paramount meaning ${ }^{20}$. The articulation of Rights, Inclusion and Order in the Declaration is only possibly because it is based in the premise that the leisure professionals and governments will evolve a singular language to make sense of and communicate the issues. This premise of common currency is reminiscent of Kant's advocacy of Reason as the triumphant agent of universal laws in human behaviour. But Kant also knew that it is a weakness in human nature to insist upon exceptions. This often takes the forms of making 'special cases' for one's own conduct, that do not conform to normative disciplinary regimes, which are seen by the individual or group as 'over-bearing' and 'over-regulated' ${ }^{21}$.

For the Declaration, this side of Kant's thinking casts a shadow over the idealist commitment to 'Rights', 'Freedom' and 'Integrity' in leisure customs and practice. It suggests that there is no final resolution towards unity, tolerance and

inclusion in leisure. The pursuit of resolution, merely creates the conditions where exceptionalism will, in time, be asserted ${ }^{22}$.

\section{What is Wrong With Globalization and Cosmopolitanism?}

The Declaration falls foul of the major criticisms that have been made of globalization and cosmopolitanism in wider 
social theory. The first of these is that there is a gap between cosmopolitan intentions of wider social inclusion, empowerment and redistributive justice, and cosmopolitan practice ${ }^{23}$. Since the early 1980's, and until the banking and financial collapse in 2008, most economists credited globalization to be one of the indisputable prime levers in increasing profit margins and wealth concentration in the elite formations of the West. The redistributive effect from the advantaged to the disadvantaged, has not plugged the development gap.

Redistributive spurts have mainly benefited metropolitan elites and remained with a compound culture. It is this stratum that has experienced the greatest degree of flexibility, choice and self determination in leisure practice. Here the desiderata of the cosmopolitan lifestyle are evident. But for the most part, they have by-passed country folk (both within the capitalist core countries and the 'developing' nation-states of the periphery). By and large, the proliferation of the low wage economy and the emergence of casual employment or significant unemployment in industrial centres that were formerly thriving have left these groups facing a struggle to maintain long standing traditions of cultural solidarity, defend leisure customs and avoid the dilemmas of poverty ${ }^{24}$.

This leads to a second major point that is presented against exponents who make the positive case for globalization and cosmopolitanism. The hiatus between the claims made on behalf of the two processes, and the record of achievement with respect to indices of Inclusion, Rights and Order, raises the spectre that elites have been over-represented both in setting the agenda, and judging the results. Elites, usually based in the metropolitan hubs of the core, have been the main economic, cultural and political beneficiaries. Outside of these spaces, many strata in the core countries have been left behind by globalization and cosmopolitanism i.e. the twin processes have either not impacted on their traditional ways of life, or they have eliminated jobs. Where jobs have disappeared, the twin processes have contributed to the revival of nationalism expressed, most trenchantly, in demands for protectionism, restrictions on migration and the revival of a law and order society. In this regard, it is probably true to say that elite interests have been well served by the vague nature of the indices of progress attached to globalization and cosmopolitanism.

To come directly to what is concrete in the Declaration here, what does it actually mean to propose that 'all persons have a need to celebrate and share diversity in leisure' (Article 2)? Is a billionaire's celebration equivalent, or in any meaningful way, comparable, with someone living on the breadline?

Article 3, makes it a requirement of governments to 'preserve and create barrier-free environments' to allow people to 'express, celebrate and share leisure'. But anyone who has been obliged to apply for an international travel visa to visit or study abroad for a period of time in a foreign country without arrangements of parity, or pay tariffs on imported goods from a trade protected zone, can testify to the forest of legal and policing impediments to global 'barrier-free environments'.

Article 5, demands that all governments will 'enact and enforce laws and policies' to further the goal of 'leisure for all'. But what sanctions or inducements are going to force governments to comply with this? A demand that fails to provide the means by which it will be enforced is toothless. It conveniently invokes progressive action at purely, an abstract level, while suffering multi-national leisure corporations to act in the way that they have always done i.e. commercializing local pastimes and traditions, and extracting maximum surplus value from participation in the profit-driven leisure bonanza. Given all of this, it is hard to disagree with Rowe's ${ }^{25}$ that the Declaration suffers from operating with 'under-theorized, totalizing constructions of global processes and effects.' Moreover, his supplementary point that world leisure organizations need to be more reflexive about how and why they are 'implicated in the very processes that they are critiquing' ${ }^{26}$.

Defenders of cosmopolitanism and globalization respond by insisting that both processes are more grounded and decisive than their detractors would have you believe. The global economy and international relations may not be functioning according to the highest ideals of cosmopolitanism, but they are part of an ongoing process, and great strides have been made ${ }^{27}$. Yet when one looks at the track record of the global institutions today that follow the cosmopolitan brief on behalf of the world the position does not seem to be so rosy. The United Nations, and the International Criminal Court are often portrayed as the very embodiment of cosmopolitanism. Their history in anticipating international conflicts, or bringing war criminals to book has been chequered. In other words, the trans-national institutions that have been created to produce understanding beyond barriers, a sense of common rights, responsibilities and joys, can claim only a partial success.

More regionally, within Europe, a cogent argument has been made that the European Union (EU) is fundamentally cosmopolitan. This is most fully articulated by Jurgen Habermas ${ }^{28}$. For him, the legacy of the European memory of the holocaust, is not only the acceptance of domestic moral responsibilities by European citizens, but an awareness of trans-national moral duties. Yet the gap between the aspirations and achievements of European cosmopolitanism as it is actually practised at the nation-state level, remains a major cause of concern. The austerity programme that Brussels and Berlin inflicted upon the ailing economies of Greece, Italy, Ireland, Portugal and Spain after the Financial crash (2008) are more reminiscent of the power politics of Metternich than Jean Monnet 29,30,31.

At the present time the reaction to globalization and cosmoplitanism is heightened by the revival of nationalism in the USA and the European Union; the persistence of the development gap between the economically advanced countries and the developing world; and the proliferation of religious antagonisms between Islamic Fundamentalism and the Christian Far Right. The Declaration is tone deaf to the causes that led to this important issues. The shadow thought of Kant on exceptionalism does not figure. When all is said and done, the Sao Paulo Declaration reproduces the central assumptions of positive, liberal perspectives on globalization and cosmopolitanism. In particular, it follows what Craig Calhoun calls, 'the attractive illusion' of the positive 
Kantian position ${ }^{32}$. Namely, that the twin processes will transcend social determinations by providing more freedom and greater universalism. Hence, the insistence in the Declaration upon 'celebrating' and 'sharing' leisure diversity and 'maintaining the freedom and integrity of leisure'.

It is unsatisfactory to think of globalization and cosmopolitanism as undifferentiated, uniform processes. Neither rolls over mankind in the same way, because mankind starts by being unequally positioned in relation to scarce resources. This unequal positioning is obscured by documents like the Declaration because they are pitched and operate in terms of what Pollock ${ }^{33}$ calls 'singular personhood'. That is, they fail to locate individual choice convincingly, in relation to material, cultural and political levels of inequality. It is these levels that position people differently and give a leisure based in freedom and integrity for some, while denying it for others. The diversity, integrity and freedom of leisure can never be a matter of individual choice or self-determination. Before an individual can chose a leisure option and participate in a leisure activity they are already positioned in relation to scarce resources. If 'freedom' and 'integrity' mean anything, they mean directly addressing the question of scarce resources, not as a side issue of individual choice, but the very fulcrum upon which individual conduct finally spins.

When all is said and done, the juxtaposition between singular personhood and abstract processes like globalization and cosmopolitanism sets a trap from which it is difficult to escape. How to get out? One promising way is to stop thinking of globalization and cosmopolitanism as blanket processes. This is not just a matter of introducing notions such as 'glocalization' to capture the idea that globalization and cosmopolitanism are not 'one way' processes. An exchange, a transference, a balance of power is always involved $34,35,36$.

It is also a matter of conceptualizing globalization and cosmopolitanism as multi-polar ${ }^{37}$. That is, within each of the twin processes, there is enormous differentiation. This means that those positioned in relation to scarce resources relate to globalization, cosmopolitanism and leisure in radically different ways. Elite formations may have experienced increased flexibility, choice and self-determination. However, formations positioned nearer the poverty line are likely to have a converse relationship with globalization and cosmopolitanism. Their experience of flexibility, choice and self-determination in leisure is threatened on many fronts. Globalization and cosmopolitanism weaken traditional leisure customs by diverting resources from localities. This often takes the form of cuts in central public finance and support for local leisure traditions. In addition, globalization often weakens local job markets by transferring jobs to the developing world or depressing local wage rates. The emergence of 'rust belt' cities in the USA, and declining industrial cities in the European Union, have increased deficit margins in local leisure economies.

\section{The Economic Dimension of the Problem}

The financial crash of 2008 intensified and exacerbated the schisms in globalization and cosmopolitanism and the quandries that arise from them. The recession has been far more severe and protracted than the economic contractions of 1974-76 and 1980-82 ${ }^{38}$. In the 18 months after the recession, US GDP declined by $4.1 \%$; UK GDP fell by $6.3 \%$; and US investment fell by $23.4 \%{ }^{39,40}$. The fall in real wages translates into a reduction in macroeconomic demand. The shortfall in liquidity has been corrected by extending the credit economy. But there are structural limits to the capacity of credit to operate as a holding measure. It is reported that in the USA home foreclosures tripled between 2006 and 2009, to almost 2.5 million. In the first quarter of 2012 consumer debt in the USA was \$11.4 trillion (of which \$904 billion was student debt) (Investor's Business Daily 1.6.2012). Students owe nearly a trillion dollars of debt, an average of $\$ 25,000$ per student. Since the crash, 25 million people in the USA have lost their jobs through factories closing ${ }^{41}$.

In July 2012 outstanding personal debt in the UK stood at $£ 1.410$ trillion. Average household debt (excluding mortgages) was $£ 5,972$. The average amount owed by UK adults (including mortgages) was £28,704. Between July 2011 and July 2012, the total interest repayments on personal debt was $£ 60.0$ billion. The Office of Budget Responsibility predicts that household debt will climb to $£ 2.044$ trillion by the end of 2017 (www. creditaction.org.uk).

Within the EU the average rate of unemployment rose from $6.7 \%$ in March 2008, to $8.9 \%$ in March 2009; leaving 21.5 million citizens without a job ${ }^{42}$. Five years later it had risen to $9.0 \%{ }^{43}$. Unemployment rates in the Southern economies in the periphery of the Eurozone are disturbingly high. In June 2014, the rate for adults $(25-74$ year olds) was $10.5 \%$; in Portugal, $12.5 \%$; in Spain, 22.4\%; in Greece 25.4\% and in Ireland $10.7 \%$. However, when one turns to rates of youth unemployment in these countries the mood of disturbance escalates to something approaching panic. In Italy, the rate for 16-24 year olds was 43.7\%; in Portugal 33.5\%; in Spain 53.5\%; in Ireland 23.2\%; and in Greece 53.1\%. Compare his with adult and youth rates in the wealth core countries of the Eurozone. In Germany, the adult rate was $4.8 \%$, and youth rate was $7.8 \%$; in Denmark, $5.5 \%$ and $12.6 \%$; in the UK, $4.6 \%$ and $17.9 \%$; in the Netherlands $6.1 \%$ and $10.5 \%$, and in France $8.9 \%$ and $22 . \$ \%$. In the USA the respective rates were $5.0 \%$ and $13.3 \%{ }^{44}$. A generation is being denied the opportunities for social mobility and building a stake in society that, for most of the postwar years have been seen as a birthright of those located in the West.

But the exposure of the credit economy as a fig leaf for major structural problems in the West does not end there. Governments that had borrowed without adequate collateral, were faced with demands from international banks and debt repayments. In particular, peripheral economies in the Eurozone, namely Ireland, Spain, Portugal, Italy and, above all, Greece, faced bankruptcy ${ }^{45}$. By and large, the fiscal and monetary stimulus measures adopted since the crash have failed to restore buoyant growth or significantly reduce accumulated debt ${ }^{46}$. Between 2008 and 2016 Governments' debt-to-GDP ratios have risen from $41 \%$ to $74 \%$, from $47 \%$ to $70 \%$ in the EU, and from $95 \%$ to $126 \%$ in Japan. High ratios usually produce an interest rate hike. Yet 
10 -year government bond rates in the USA are currently $2 \%$, around $0.5 \%$ in Germany and around $0.2 \%$ in Japan. Since 2008 , despite near zero rates in the USA, and real interest rates of zero in the Eurozone, the West has been in a condition of 'secular stagnation' ${ }^{47}$. That is, a structural condition in which there is a serious imbalance between an increasing propensity to save and a decreasing propensity to invest. This disequilibrium depresses economic activity by compounding funds in banks, financial management organizaton's and fixed assets. Low liquidity makes the problem worse. The brief spurt in growth in America between 2003 and 2007, was reliant upon the transference of unsustainable levels of savings into insupportable levels of investment. This produced the housing crisis.

The increasing propensity to save is the product of many factors. Among the most significant are the rising inequality gap between the rich and poor, new uncertainties about the retirement age, threats to the stability of benefits produced by austerity programmes and a greater concentration of assets in foreign central banks and sovereign wealth management funds. The impact on the inequality gap in the Anglophone countries is severe. In the USA, the top $0.1 \%$ of families have increased their share of wealth, decade by decade. It expanded from $7 \%$ in 1978 , to $22 \%$ in $2012^{48}$. Over the same period, the value of real wages has fallen. In the UK, between 1980 and 2011, wage share of output fell from 59.1\% to 53.7\%. Between 1990 and 2009 , the median wage across the OECD member states declined from $66.1 \%$ to $61.7 \%{ }^{49}$. In the Anglophone, governments have displayed a stubborn reluctance to apply fiscal measures against the richest in society. Instead, generally speaking, public policy has concentrated upon applying austerity measures of various degrees of intensity. These have had the most damaging effect on people on or near the poverty line. In addition, cuts in public expenditures have increased the leisure deficit in local economies and reinforced the trend to weaken local leisure traditions.

\section{Conclusion}

It is no part of my argument to accuse the architects of the Sao Paulo Declaration (1998) of bad faith. In drawing up the document they were not acting on behalf of the interests of the global elites in business, government or military relations. On the contrary, the Declaration displays idealism in respect of its commitment to the principle that 'all persons have the right to leisure'. Nor were the architects wrong in proposing that globalization and what we now call, cosmopolitanism, amount to a tectonic challenge to orthodox ways of conceptualizing and practising leisure. However, despite the acknowledgement that some aspects of globalization constitute threats to leisure, notably in relation to the over-commercialization of practices, risk and other 'abuses and misuses', the Declaration is far too sanguine. It fails to grasp that globalization and cosmopolitanism do not simply enrich social and economic exchange. They also impoverish leisure experience for what, following the election of Donald Trump as President, and the Brexit vote of 2016, have become known as 'the left behind'. These are the strata in the capitalist core who have seen their leisure traditions undermined by centrally directed programmes of austerity, static or falling real wages, the onslaught of casualized labour and unemployment, rising property prices making housing unaffordable and the rising costs of tertiary education. In what sense can the defence of integrity and freedom in leisure customs and practice be spoken of, in a social and economic condition where many people, especially, those of adult age between 18 and 30 , cannot expect to own their own home or cover their own health costs?

The optimism of the Declaration is over-blown. For example, Article 8 grandly calls upon 'all private and public spheres' to implement policies designed to 'provide leisure education curricula and programmes for school and community systems.' What is the point of such an education if people do not have full time work that enables them to earn an income that can meaningfully support leisure choices or live in affordable housing? The net effect of undertakings, like Article 8 , is to make many people, again, specifically young people, regard the architects of the Declaration to be out of touch with the lives of ordinary folk.

The lack of grounded reality in the Sao Paulo declaration exposes its tactics as faulty. A rule of effective politics is that it is unwise to make promises that have a small chance of being fulfilled. The Declaration is awash with undertakings of this sort. 'All persons have the right to leisure'; 'all governments and institutions should preserve and create barrier-free environments'; 'all governments will enact and enforce laws and policies designed to provide leisure for all'; these are laudable objectives, but they are only convincing if clear headway can be made to sustain them. Since 1998, his has not been achieved. The schisms in globalization and cosmopolitanism have renewed nationalist demands.

The effect of the decline in the labour market and the erosion of local customs and traditions is demonstrable in the rise of a 'new Caesarism' in the European Union ${ }^{[4]}$. Geert Wilders and the Party for Freedom movement in the Netherlands; Marine Le Pen and the Front National in France; Nikolas Michaioiakos and the Golden Dawn Party in Greece; the AfD (Alternative for Germany) in Germany; and Boris Johnson, Michael Gove in the Brexit movement in the UK, are all in favour of increasing protectionism, raising barriers to reduce migration and impede the free movement of labour and increase law and order provisions. This is mirrored with President Trump's exploitation and heightening of nationalism in the USA and Vladimir Putin's authoritarian populism in Russia. None of this bodes well for either globalization or cosmopolitanism. It suggests that the multipolar character of the twin processes produces divisions

[4] The 'New Caeserism' is a term invented by Oswald Spenger in his famous book The Decline of the West 56. Spengler argued that one symptom of the decline of the West was the tendency of Plebiscitary Parliamentary Democracy to perpetually promise what it perpetually fails to deliver. Politically speaking, the system produces regular crises. In times of major crises, there is a tendency for 'strong leaders' to emerge and dominate. 
between cosmopolitanism and nationalism in single countries that contribute to the paralysis of the political system and increase the risk of civil unrest.

One side effect of this is that leisure relations are likely to become more politicized. There is the question of protecting traditional leisure traditions that have been undermined by centralized austerity programmes. This is reason enough for people who feel that organized politics have not listened to them and even, not recognized them, estranged from a system that seems loaded for the rich ${ }^{50}$. Perhaps of greater longer term significance is the issue of educating and supporting people to exercise their right to leisure in meaningful ways. Of central importance here is how to revitalize leisure experience in the midst of the contraction in the labour market caused by globalization. One important aspect of this is the emergence of new robot intelligence technologies, which point to a deepening of labour market contraction. Immense claims are being made for the impact on lifestyle and safety of driverless cars ${ }^{51}$. It is estimated that driverless cars will create 320,000 jobs in the UK ${ }^{52}$. The introduction of robotic labour into the service sectors of transport, health care, education is set to escalate. Automation has long been a conventional feature of advanced industrialization. Fordism was based upon it. What is new about the industrial revolution of our own times is that automated labour is no longer confined to standardized tasks. Increasingly robotic labour adds value by producing non-routine and cognitive tasks. The inevitable effect is to shed human labour. Mass unemployment is not politically sustainable. However, the new industrial revolution offers opportunities to think outside of the world of globalization, cosmopolitanism, work and leisure envisaged by the Sao Paulo Declaration. One aspect of this is to take seriously the idea of introducing Universal Basic Income (UBI), payable to all citizens on reaching majority . A second pressing concern is to address the global wealth gap ${ }^{53}$. In 2016 Global Wealth was estimated to be USD 256 trillion. The wealthiest $10 \%$ of the world's population own $89 \&$ of all global assets. The poorest $50 \%$ own global assets worth less than $1 \%$ of the total. Between 2010-2015 the wealth of the richest 62 people in the world rose by $45 \%$, while that of the poorest $50 \%$ fell by $38 \%$ (Credit Suisse 2016). Article 3 of the Declaration submits that government should create and 'barrier free environments' to pursue freedom, integrity and diversity in leisure customs and practice. The greatest barrier facing globalization and cosmopolitanism is the global wealth gap. It requires leisure professionals and governments to apply fiscal policies and judicial measures to tackle vested interests. If this is not done, documents like the Sao Paulo Declaration will be ineffectual. It does not have and it has not built a 'consensual programmatic dimension'. Everything points to the conclusion that world conditions in technology, economic distribution and risk factors, require leisure professionals to become far more political.

[5] The term 'Majority' her refers to the legal age in which citizens are entitled to vote.

\section{References}

1. Held D, McGrew A. Global Transformations, In: Goldblatt D., Cambridge, Cambridge Perraton. J. University Press, 1999.

2. Beck U. The Cosmopolitan Society And Its Enemies. Theory Cult Soc. 2002; 19(1-2):17-44.

3. Ritzer G, Paul D. Globalization: a basic text, London: Willey Blackwell, 2015.

4. Delanty G. The Cosmopolitan Imagination. Cambridge University Press, 2008.

5. Calhoun $\mathrm{C}$. Belonging in the Cosmopolitan Imaginary. Ethnicities. 2003; 3(4):531-53.

6. Waldron J. What Is Cosmopolitanism? J Political Philos. 2000; 8(2):227-243.

7. Beck U. The Cosmopolitan Vision, Cambridge. Polity. 2006.

8. Cheah P. Inhuman Conditions: On Cosmopolitanism and Human Rights. Cambridge, Harvard University Press, 2007.

9. Singer P. One World: The Ethics of Cosmopolitanism. New Haven, Yale University Press, 2004.

10. Nussbaum M. Patriotism and Cosmo-politainism. Boston Rev. 1994; 19(5):3-34.

11. Matthewman S. Disasters, Risks and Revelation: Making Sense of Our Times. London, Macmillan, 2015.

12. Couldry N, Hepp A. The Mediated Construction of Reality. Cambridge, Polity, 2016.

13. Rojek C. Presumed Intimacy: Para-Social Relationships. In: Media, Society and Celebrity Culture, Cambridge, Polity, 2016.

14. Rojek C. Presumed Intimacy: Para-Social Relationships. In: Media, Society and Celebrity Culture, Cambridge, Polity, 2016.

15. Du Bois, WB. The Souls of Black Folk. Oxford, Oxford University Press, 1903.

16. Skrbis Z, Woodward I. Cosmopolitanism: Uses of the Idea. London, Sage, 2013.

17. Wahab S, Cooper C, editors. Tourism in the Age of Globalization. London, Routledge, 2001.

18. Bairner A. Sport, Nationalism and Globalization. Albany, State University of New York Press, 2001.

19. Nalani B, Dzikus L. Sport Labour Migration: Understanding Leisure Activities of American Professional Basketball Players Abroad. Leis Stud. 2015; 34(1):67-81

20. Gellner E. Nations and Nationalism. Oxford, Blackwell, 1983.

21. Kant I. Critique of Pure Reason London, Penguin, 2007.

22. Rojek C. Decentring Leisure. London, Sage, 1995.

23. Pollock S. Cosmopolitanism and Vernacular in History. In: Breckenbridge $\mathrm{C}$, Pollock S, Bhabba H, Chakarabarty D. (eds) Cosmopolitanism, Durham, NC: Duke University Press, 2002. p. 15-53.

24. Easterly, W. The White Man's Burden. Oxford, Oxford University, Press, 2007.

25. Rowe D. Coming to Terms with Leisure and Globalization. Leis Stud. 2006; 25(4):423-436. 
26. Rowe D. Coming to Terms with Leisure and Globalization. Leis Stud. 2006; 25(4):423-436.

27. Beck, U. The Cosmopolitan Society And Its Enemies. Theory Cult Soc. 2002; 19(1-2):17-44.

28. Habermas J. The Postnational Constellation: Political Essays. Cambridge, Polity, 2001.

29. Streeck, W. How Will Capitalism End? London, Verso, 2016.

30. Varoufakis, Y. And the Weak Suffer What They Must? London, Penguin, 2016.

31. Varoufakis, Y. Adults in the Room. London, Bodley Head, 2017.

32. Calhoun $\mathrm{C}$. Belonging in the Cosmopolitan Imaginary. Ethnicities. 2003; 3(4):531-53.

33. Pollock S. Cosmopolitanism and Vernacular in History. In: Breckenbridge $\mathrm{C}$, Pollock S, Bhabba $\mathrm{H}$, Chakarabarty D. (eds) Cosmopolitanism, Durham, NC: Duke University Press, 2002. p. 15-53.

34. Salazar, NB. Tourism and glocalization "Local" Tour Guiding. Ann Tour Res. 2005; 32(3):628-48

35. Roudometof V. Theorizing Globalization: Three Interpretations. Eur J Soc Theory. 2016; 19(3):391-408

36. Mohammed R. Glocalization and the Media Studies from the South. Int Stud Perspectives. 2013; 50(3):240-254.

37. Nederveen P. Multipolar Globalization. London, Routledge, 2017.

38. Pontusson J, Raess D. How and Why is this time Different? The Politics of Economic Crisis in Western Europe and the United States. Annu Rev of Political Science. 2012; 15:13-33.

39. Labonte M. The 2007-9 Recession: Similarities to and Differences from the Past, CongressionalResearch Service, 2010. Available from: http://fas.porg/sgp/crs/misc/R40198. pdf [Accessed 6th October 2017]

40. Crocker G. Keynes, Piketty and Basic Income. J Law Econ. 2015; 10(1):91-113.

41. Bellamy Foster J. The Household Debt Bubble. Monthly Review. 2006; 58(1):1-11

42. Kern A, Marien S, Hooghe, M. Economic Crisis and Levels of Political Participation in Europe (2002-2010): The Role of Resources and Grievances. West Eur Politics. 2015; 38(3):465-90.

43. Bell D, Blanchflower D. Youth unemployment in Greece: measuring the challenge. IZA J Eur Lab Stud. 2015; $4(1): 1-25$.
44. Bell D, Blanchflower D. Youth unemployment in Greece: measuring the challenge. IZA J Eur Lab Stud. 2015; $4(1): 1-25$.

45. Streeck W. How Will Capitalism End? London, Verso, 2016.

46. Caporaso J, Rhodes M. The Political and Economic Dynamics of the Eurozone Crisis (editors). Oxford, OUP, 2016.

47. Summers L. The Age of Secular Stagnation. Foreign Affairs February 15, 2016.

48. Saez E, Zucman E. Wealth Inequality in the United States Since 1913: Evidence from Capitalized Income Data. Q J Econ. 2016; 131(2):519-578.

49. Crocker G. Keynes, Piketty and Basic Income. J Law Econ. 2015; 10(1):91-113.

50. Wolin S. Democracy Inc. Princeton, Princeton University Press, 2008.

51. Duranton G. Transitioning to Driverless Cars. Cityscape. 2016; 18(3):193-196.

54. McBride N. The Ethics of Driverless Cars. Computers \& Society. 2015; 45(3):179-84.

53. Branko M. The Haves and rhe Have-Nots. New York, Basic Books, 2012.

54. Scheffler S. Boundaries and Allegiances. Oxford, Oxford University Press, 2001.

55. Horton D, Wohl R. Mass communication para-social interaction. Psychiatry. 1956;19:215-229.

56. Spengler O. The Decline of the West. An Abridged Edition, 1994.

\section{Corresponding author}

Cesar Teixeira Castilho

Universidade Federal de São Joao del-Rei, Physical Education raça Frei Orlando, 170, Centro Sao Joao del-Rei Minas Gerais, Brazil.

Email: castcesarster@gmail.com

Manuscript received on January 17, 2018

Manuscript accepted on March 25, 2018

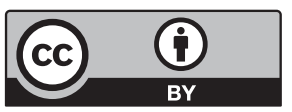

Motriz. The Journal of Physical Education. UNESP. Rio Claro, SP, Brazil - eISSN: 1980-6574 - under a license Creative Commons - Version 3.0 